\title{
COTIDIANO, CORPO E PROCESSOS DE SUBJETIVAÇÃO NA ESPIRAL POÉTICA DE RUBIANE MAIA
}

DAILY LIFE, BODY AND SUBJECTIVATION PROCESSES IN RUBIANE

MAIA'S POETIC SPIRAL

\section{Lindomberto Ferreira Alves}

PPGA-UFES

Resumo: $\mathrm{O}$ artigo investiga como que corpo, cotidiano e processos de subjetivação são agenciados nos processos artísticos de Rubiane Maia. Persegue-se, aqui, a hipótese de que esses três verbetes se constituem como eixos norteadores dos deslocamentos poéticos explorados no decurso dos seus primeiros dez anos de carreira. Busca-se situar em perspectiva suas intenções poéticas de indissociação entre vida e obra - tendência que, em Rubiane Maia, parece conduzi-la à afirma-ção de um horizonte mais expansivo de relações entre a arte e a vida.

Palabras-chave: Rubiane Maia, processos criativos, arte e vida.

Abstract: The article investigates how the body, daily life and processes of subjectivation are acted on Rubiane Maia's artistic processes. The hypothesis that these three entries are the guiding axes of the poetic displacements explored during the first ten years of her career is pursued here. The aim is to place in perspective her poetic intentions of indissociation between life and work - a tendency that, in Rubiane Maia, seems to lead her to the affirmation of a more expansive horizon of relationships between art and life.

Keywords: Rubiane Maia, artistic processes, art and life. 


\section{Introdução}

Este artigo tem por objetivo perscrutar como que corpo, cotidiano e processos de subjetivação são agenciados no universo dos processos artísticos da artista multimídia contemporânea Rubiane Maia ${ }^{1}$. Trata-se de um dos nomes relevantes da geração de performers, brasileiros e estrangeiros, à qual pertence, bem como um dos nomes centrais da produção contemporânea em Artes Visuais no Espírito Santo, surgidos

1 Rubiane Maia é Licenciada em Artes Visuais (2004) pela Universidade Federal do Espírito Santo (UFES) e Mestre em Psicologia Institucional (2011), pela mesma instituição. Nascida em Caratinga/MG e radicada em Vitória/ES desde os quatro anos de idade, atualmente Rubiane Maia vive entre Vitória (Espírito Santo, Brasil) e Folkestone (Reino Unido), percorrendo o mundo com seus trabalhos nas áreas da performance, do vídeo, da fotografia e do cinema, apresentando as possibilidades de expansão das potências do corpo, alinhada ao 'cuidado de si' (FOUCAULT, 2004), por meio das mais diversas experiências performativas. Entre os anos de 2006 e 2019 seus trabalhos foram apresentados (presencialmente ou sob a forma de vídeos e performances em live stream), mais de uma vez, em eventos de 13 países (além do Brasil), a saber: Inglaterra, México, Bolívia, Portugal, Argentina, Espanha, França, Lituânia, Chile, Irlanda, Itália, Estados Unidos e Trinidade e Tobago. Realizou 18 residências artísticas, sendo nove no Brasil e outras nove em cidades de um dos países acima mencionados. Integrou 21 exposições coletivas - sendo 17 realizadas no Brasil, das quais se destacam "Modos de Usar" (Vitória/ES, 2015), "Terra Comunal - Marina Abramović + MAI" (São Paulo/SP, 2015), "Das virgens em Cardumes e da Cor das Auras" (Rio de Janeiro/RJ, 2016) e "Negros Indícios" (São Paulo/SP, 2017); e quatro realizadas fora do país, cujos destaques são "9th Kaunas Biennial UNITEXT" (Lituânia, 2013), "PASSE/IMPASSE” (Espanha, 2016) e "Jerwood Staging Series Sensational Bodies” (Londres, 2018). Ademais, publicou no Brasil o livro "Autorretrato em Notas de Rodapé" (Vitória/ES, 2014), fez a exposição individual "À Primeira Vista: uma maçã e duas cadeiras” (São Paulo/SP, Brasil, 2015), produziu os curtas-metragens “EVO" (2015) e "ÁDITO" (2017) - exibidos, até o momento, em dez (10) festivais de cinema nacionais e internacionais. Tal retrospecto the rendeu, no ano de 2017, a indicação em uma das mais importantes e relevantes premiações no âmbito da produção nacional de Arte Contemporânea, o "Prêmio PIPA". Para mais informações sobre Rubiane Maia, bem como sobre o conjunto da obra da artista, ver: <http://cargocollective.com/rubianemaia>. no começo do século XXI. Até o momento, um dos nomes que conseguiu maior inserção no cenário artístico nacional e internacional, participando de diversos eventos importantes no campo das artes performáticas, no Brasil e em outros cantos do mundo - a ponto de se tornar, atualmente, uma das mais reconhecidas performers no cenário brasileiro contemporâneo.

Em virtude da escassez de publicações da área que ascendam o interesse na pesquisa teórica e no exercício crítico sobre a produção artística de Rubiane Maia, estabelece-se, aqui, um pontapé inicial num percurso de reflexão em torno dos processos artísticos dessa artista. Esforço esse que enseja a construção de uma fortuna crítica sobre sua obra, contribuindo tanto para a difusão da arte produzida por Rubiane Maia, aqui e no mundo, quanto para a inserção do seu projeto poético no radar da crítica de arte no contemporâneo.

Visando um recorte circunscrito, persegue-se a hipótese de que esses três verbetes - cotidiano, corpo e processos de subjetivação - se constituem, ao mesmo tempo, como eixos norteadores dos deslocamentos poéticos explorados no decurso dos seus primeiros dez anos de carreira, e como chaves de decifração do espaço-tempo da criação desta artista. Tendo como ponto de partida as considerações dos filósofos franceses Michel Serres e Bruno Latour sobre o tempo à luz da multiplicidade e, tomando como aporte discursivo as impressões da artista a respeito dos processos de criação engendrados entre os anos de 2006 e 2016, essas reflexões pretendem situar em perspectiva suas intenções poéticas de indissociação entre vida e obra. Tendência que no âmbito do projeto poético de Rubiane Maia parece conduzi-la à afirmação de um horizonte mais expansivo de relações entre a arte e a vida. 


\section{Espiral poética: ou, o espaço-tempo dos pro- cessos artísticos de Rubiane Maia}

De imediato, uma tomada de posição. Embora o percurso artístico de Rubiane Maia - empreendido entre os anos de 2006 e 2016 - possa ser analisado a partir de uma estrutura cronológica e linear; enquanto forma, esse tipo de organização não dá conta de expressar os desdobramentos poéticos desta artista, acabando por confinar Rubiane e seus trabalhos a um tempo linear, distanciado e apartado do tempo como multiplicidade pura², como propôs o filósofo francês Michel Serres (1982; 1999).

Ainda segundo esta linha de raciocínio, se observadas, com atenção, as questões conceituais e formais que perpassam o conjunto da obra de Rubiane Maia, perceberemos que a noção de espiral do tempo ${ }^{3}$, evocada pelo filósofo

2 Para Michel Serres (1982; 1999), o tempo corre segundo uma "variedade extraordinariamente complexa, como se aparentasse pontos de paragem, rupturas, poços, chaminés de aceleração espantosa, brechas, lacunas, tudo semeado aleatoriamente, pelo menos numa desordem visível" (SERRES, 1999, p. 83). Serres perscruta, portanto, a ideia de diferenciação em tempos elementares múltiplos - contrária a representação formal do tempo como uma linha, contínua ou entrecortada. É a partir desse prisma que o filósofo vai sugerir o tempo como turbulento, bifurcado, dobrado, caótico e paradoxal, fluindo sempre de maneira complexa, inesperada e complicada. Um tempo livre de qualquer teleologia, que "dobra-se ou torce-se; [...] uma variedade que seria necessário comparar à dança das chamas de uma fogueira: ora cortadas, ora verticais, móveis e inesperadas" (SERRES, 1999, p. 84). Nele, não existiria uma distância medida, geométrica, fixa e mensurável entre as coisas, apenas topologia: "ciência das vizinhanças e dos rasgões” (SERRES, 1999, p. 87).

3 Entusiasta das reflexões serresianas sobre o tempo como multiplicidade pura, Bruno Latour (1994) elabora a noção de espiral poética no intento de atribuir contornos à compreensão da passagem do tempo na qual seria possível vislumbrar uma reconexão com a liberdade de movimento do tempo à luz da multiplicidade. Com esta noção, Latour esboça seu interesse por uma passagem do tempo cuja temporalidade não nos força “o uso de etiquetas 'arcaico' ou 'avançado', já que todo agrupamento de elementos contemporâneos pode juntar elementos pertencentes a todos os tempos" (LATOUR, 1994, p. 74). francês Bruno Latour (1994), mostra-se bastante adequada para pensarmos a passagem das diferentes temporalidades inerentes aos deslocamentos dos processos artísticos e criativos de Rubiane - posto que esses revelam múltiplos atravessamentos, continuidades, repetições, rupturas e desvios, que escapam a lógica do encadeamento cronológico.

Juntas, as considerações de Michel Serres e Bruno Latour ao redor do tempo à luz da multiplicidade, aguçaram a percepção da amplitude, da densidade e da complexidade das tramas poéticas que tecem o espaço-tempo da criação em Rubiane Maia, de modo especial neste recorte temporal. Afinal, se por um lado a progressão ${ }^{4}$ no desenvolvimento dos sessenta trabalhos ${ }^{5}$, produzidos nesse interim, cunhou uma trajetória artística expressiva e bastante consolidada, o fazer artístico de Rubiane, por outro, embaralha o tempo linear, proliferando para além dele. É o que fica evidente em suas próprias palavras:

a contagem do tempo me parece super abstrata [...] o que vejo é que o contexto muda, as questões se ampliam e vão adquirindo maior complexidade, a gente entra e sai de muitos emaranhados, mas não existe isso de começomeio-fim (SILVA, 2018 apud ALVES, 2020, p. 118).

Ao projetar sua atenção no presente, nesta "estreita nesga entre o passado e o futuro e cuja definição depende das definições de passado e

\footnotetext{
4 Conforme aponta Michel Serres (1968), progressão em Leibniz não teria nada a ver com univocidade e linearidade, como se ela fosse global e simples. Tratar-se-ia, sim, de uma noção indefinidamente diferenciável, cujo processo aciona "evoluções regionais, acelerações parciais, regressões temporais, alternâncias, equilíbrios, transformações finas" (SERRES, 1968, p. 284).

5 Para visualizar os registros memoriais, bem como as imagens referentes a esse volume de trabalhos, acessar: <https://www.rubianemaia.com/>.
} 
futuro" (SANTOS, 1996, p.10), a artista revisita e desloca o passado da condição de lembrança, atualizando-o. Operação cuja força mobiliza, aproxima, contamina e dobra ${ }^{6}$ os estudos, as pesquisas, as experimentações que, retornam em diferentes registros, acumulados sob camadas de distintos processos artísticos. Tanto a noção serresiana de tempo como multiplicidade pura quanto a noção latouriana de espiral do tempo, colocam uma lente de aumento que amplifica e traz para o visível e dizível, aquilo que poderia não emergir por contra própria, a saber: que o fazer artístico de Rubiane Maia seria urdido através do que propus chamar de espiral poética.

Imagem que parece prefigurar a aposta bastante consciente do fazer artístico de Rubiane na importância dos atravessamentos politemporais, de modo que a relação entre sua poética - entendida como urgência diante da precariedade humana (física, mental, emocional, social, existencial) - e a força do contemporâneo seja potencializada em suas ações, volua?. A cada volta dessa espiral, seu fazer artístico nada tem a ver com um tempo que prometa a superação ou a revolução, mas sim com o tempo como multiplicidade pura; eterno retorno das questões, dos temas, dos elementos marcados sempre pelo signo da diferença. Retomando o que Bruno Latour esclarece a respeito da espiral do tempo, nesse arranjo:

6 Ao falar sobre o barroco, Gilles Deleuze (1991) pondera que esse estilo não inventou as coisas sobre as quais se apropriou, mas ele as curvou e descurvou, realizando dobras e levando-as ao infinito.

7 Trata-se de um conceito desenvolvido pelo "Grupo Informáticos”, formado na Universidade de Brasília, em 1992. Para Medeiros (2017, p. 42), é um conceito que "pode sugerir sinais nomadizantes para pensar a arte contemporânea: [...] volução não é evolução, nem devolução, nem involução. Na volução não há progresso nem novidades. Nada é novo, tudo volui, re-volui e é iteração. Há volução, processos em voluta, em espiral rodando sem objetivo, sem jamais atingir o centro (inexistente), sem jamais manter um só movimento". certamente temos um futuro e um passado, mas o futuro se parece com um círculo em expansão em todas as direções, e o passado não se encontra ultrapassado, mas retomado, repetido, envolvido, protegido, recombinado, reinterpretado e refeito. Alguns elementos que pareciam estar distantes se seguirmos a espiral podem estar muito próximos quando comparamos os anéis. Inversamente, elementos bastante contemporâneos quando olhamos a linha tornam-se muito distantes se percorremos um raio (LATOUR, 1994, p. 72).

Pois bem, diversas questões, temas e elementos voluem nesse arranjo espiralado poético de Rubiane Maia. E isso porque eles estão permanentemente se cruzando nesse tempo de criação em espiral que parece se expandir em todas as direções. No limite, o fazer artístico de Rubiane Maia parece estar em constante relação com as intensidades da passagem do tempo à luz da multiplicidade; procedimento que, remetendo ao argumento de Cecília Almeida Salles (2006) a respeito da criação como rede em construção, seria sempre marcado "por sua dinamicidade que nos põe, portanto, em contato com um ambiente que se caracteriza pela flexibilidade, não fixidez, mobilidade e plasticidade" (SALLES, 2006, p. 12). Um fazer que, à maneira deleuziana, opera por meio de dobras, da multiplicidade de arranjos, conexões e atravessamentos - dado que "o múltiplo não é só o que tem muitas partes, mas que é dobrado de muitas maneiras" (DELEUZE, 1991, p. 13-14).

É o que podemos notar, por exemplo, nos processos artísticos vinculados às pesquisas de Rubiane que mobilizam os verbetes cotidiano, corpo e processos de subjetivação - presentes desde os seus primeiros trabalhos. Trata-se de disparadores conceituais cuja amplitude e complexidade inerentes a cada um, foram permitindo à artista, em diferentes momentos e a partir 
de diferentes perspectivas, trabalhá-los e retrabalhá-los tanto a partir de novas articulações e composições, quanto a partir da repetição de uma dada articulação e/ou composição - marcadas sempre por intensidades distintas.

Cada vez que eles vão sendo retomados, diz Rubiane: "eles me trazem uma percepção diferente do tempo, dos afetos, das simbologias" (SILVA, 2020 apud ALVES, 2020, p. 121). Note-se que neste quadro seus processos artísticos tornam-se politemporais; operam uma liberdade de movimento de seleção daquilo que faz parte do tempo da criação - fazendo com as questões, os temas e os elementos voluam, se dobrem, se conectem e pertençam, simultaneamente, a tempos diferentes.

Isso porque cada cruzamento é uma oportunidade, segundo a artista, para "esgotar ou, pelos menos, tentar esgotar algumas possibilidades, [...] continuar experimentando algumas possibilidades dessas relações" (Ibidem, p. 122) entre trabalhos e processos, assim como entre as questões, os temas e os elementos que o compromisso com as palavras concisão e esgotamento mobilizam no âmbito de seus processos criativos $^{8}$. Isto exposto, por ora, importa à

8 De acordo com a artista, "eu encaro a concisão como um aspecto que me trouxe mais minimalismo para o meu trabalho. Porque com ela, eu comecei a pensar e a gostar muito da ideia de que esgotar uma ideia. E esgotar uma ideia, um conceito, pode gerar não uma, mas muitas performances. Então todas as vezes que eu tenho uma ideia, para desenvolver um trabalho, eu tento limpar. O que não é essencial? O que não é super importante? Se isso não é super importante, eu corto. Ou, então, se isso é tão importante e está competindo com outro, muito importante, eu divido. Isso virou uma espécie de metodologia de trabalho, que eu aplico até hoje" (SILVA, 2020 apud ALVES, 2020, p. 121). Nesse sentido, se por um lado, a ideia de concisão, no âmbito de seus processos criativos, revela sua aposta no mínimo, no detalhe, naquilo que, a princípio, parece insignificante - e que, juntas, numa única ação, perderia sua potência por levar para muitas questões diferentes. Por outro, a ideia de esgotamento parece aludir a sua aposta nos múltiplos continuidade da presente discussão aferir como cotidiano, corpo e processos de subjetivação permeiam o universo artístico de Rubiane Maia, em direção ao entendimento de como essa sua espiral poética - prenhe de dobraduras forjadas nesse seu tempo de criação espiralado - os mobiliza de modo singular.

\section{Cotidiano, corpo e processos de subjetivação na espiral poética de Rubiane Maia}

Em primeiro lugar, é importante destacar que essa ideia de volução do tempo da criação dos processos artísticos de Rubiane Maia se torna indissociável, desde os trabalhos iniciais, do seu próprio cotidiano. Sobre ele, seu processo criativo, diz ela: "é dinâmico, não é nada fixo, está incorporado no meu modo de tentar me entender no mundo" (SILVA, 2018 apud ALVES, 2020, p. 122). Nesses termos, ao assumir o cotidano ao mesmo tempo como espaço-tempo de e da criação, Rubiane o conjura a "um desejo de arte que diz de um desejo de vida” (SILVA, 2011, p. 97).

Bem, se partirmos do pressuposto de que o cotidiano pode ser visto como "um terreno fértil para a reflexão, a percepção e a imaginação dos modos e das experiências do real; um terreno repleto de microssaberes que permitem discernir tendências sociais, culturais e políticas" (VINÍCIUS, 2010, p. 24); é justamente a partir dele que a artista passa a recolher as matérias de expressão de seus processos criativos. Matérias implicadas em um compromisso com os deslocamentos do desejo de expressão e recriação de sua própria cotidianiedade, na busca por vias de afirmação criativa que permitam que a sua vida siga seu fluxo por caminhos mais potentes.

desdobramentos que uma única ideia pode evocar quando decomposta em frames, os quais poderão ser acionados, retomados, refeitos, recombinados em temporalidades distintas e, consequentemente, reinterpretados segundo diferentes interesses e necessidades em constante volução. 
Assim, ao perseguir e extrair de seu cotidiano a alteridade, seus processos não só afirmam a condição de criação de outros mundos e novos modos de vida pela arte. Mas, também, experimenta, explora, processa e projeta saídas

do mesmo para a busca de outro de si, de outro de nós. Instância dos encontros que permitem algum estreitamento com o sensível; subjetividades convocadas a deslocamentos e desvios frente a tanta massificação; diferenças vividas como potência de resistência ou re-existência" (SILVA, 2011, p. 97).

Nota-se aí, o quanto o ponto de partida primordial da singularidade poética de Rubiane Maia parece estar vinculado a um movimento que procura mobilizar a convergência de processos de transformações latentes entre arte e vida, via práticas que possuem como fatores determinantes a escuta e a atenção às paisagens psicossociais ${ }^{9}$ da contemporaneidade. Práticas que ao travar um confronto com o seu cotidiano, especialmente naquilo que diz respeito aos modos de funcionamento e regulamentação vigentes da vida aí operados, acompanham e instauram "o desmanchamento de certos mundos - sua perda de sentido - e a formação de outros” (ROLNIK, 2011, p. 23).

Em outras palavras, práticas que produzem um modo de pensar e de agir favorável às linhas de resistência de um mundo-crise ${ }^{10}$, capazes de

9 Para Suely Rolnik (2011), os mundos que habitamos são paisagens fugazes sempre em movimento que ela denomina como paisagens psicossociais, constituídas a partir do encontro entre corpos, agenciamentos e cristalizações de desejo. Elas remetem a estéticas circulantes e formas coletivas de subjetividade, modos históricos de produção de corpo, do desejo e de relação com os outros e consigo mesmo - estetizações e formas históricas de elaboração e produção de si. Delineamento dinâmico não focado nem centrado nos sujeitos, mas em relações e jogos de força onde sua constituição está em questão.

10 Expressão ligada ao debate político que perpassa a "partilhar o sensível, embaralhar os códigos e afrouxar certas lógicas entre a ética, a política e a estética" (SILVA, 2011, p. 71). Movimento que ao tensionar a arte no seio dos jogos de força que atravessam o panorama da vida contemporânea, evoca outros agenciamentos, outras significações, outros afetos, outros desejos, outros territórios, outras identificações, outras linguagens - em suma, outras cotidianidades nas quais a vida possa se afirmar e se realizar como pura potência.

Se o cotidiano parece se constituir como espaço-tempo por onde o tempo da criação dos processos artísticos de Rubiane volui, é de fundamental importância frisar, em segundo lugar, que é no corpo - no próprio corpo da artista - que ele é agenciado. Algo que é reforçado em seu statement - espécie de carta de intenções que sintetiza sua proposta artística - na qual declara o interesse em "[...] fazer uso do corpo para ampliar suas possibilidades de percepção para além do habitual, por meio de uma constante (re)elaboração de sua própria noção de território existen-

noção foucaultina de biopolítica e que estabelece uma crítica social sobre o modo de viver adequado à forma social capitalista. Michel Foucault (2008) entende biopolítica como um modo de funcionamento político que, desde o século XVIII, passou a operacionalizar a prática governamental sobre conjuntos de viventes, em direção a tomada do corpo, da saúde, das ideias, da subjetividade, da vida. Biopolítica: poder sobre a vida; produção e reprodução da vida e da subjetividade que atendam à organização social capitalista. Vale destacar, ainda, as importantes contribuições no cenário atual do filósofo camaronês Achille Mbembe, em torno da atualização da noção de biopolítica. Para Achille Mbembe (2018), haveria um direcionamento da biopolítica para o que ele chama de necropolítica. Ao cruzar a questão da classificação social pautada na raça e no modo de viver neoliberal contemporâneo, o filósofo demonstra que não se trata apenas de um poder sobre a vida, mas uma expulsão da humanidade e necessária mortificação social, corporal e psíquica - eliminação dos considerados inimigos da soberania do Estado - onde o "deixar viver" e o "deixar morrer" são conduzidos à formação de populações direcionadas à homogeneização social. 
cial (espacial, temporal, social, cognitivo etc.)" (SILVA, s/d apud ALVES, 2020, p. 124).

Perceba que Rubiane parece saber muito bem que qualquer tentativa de alinhamento de seus processos criativos ao entendimento de suas relações com as cotidianidades do mundo - visando, aí, a instauração de outros modos de olhar e de estar na vida, outros modos de olhar para si mesma e para o mundo contemporâneo - passa, necessariamente, pelo corpo, ou melhor, pelos usos que faz do seu corpo. Isso porque são das gestualidades que emanam desse corpo ante as intervenções, as linhas de fuga, as bifurcações, os devios e as fricções entre ele e o meio que efetivamente se desvelam os "arranjos e rearranjos desse corpo em relação aos espaços-tempos do viver" (SILVA, 2011, p. 100) - conduzindo-a, portanto, ao encontro "da vida como processo" (Ibidem, p. 96).

Assim, em Rubiane, os usos do próprio corpo parecem ser operados como uma espécie de ferramentaria polifônica de processos, a serviço de "experiências táteis, motoras, cinestésicas e, particulamente visuais” (GLUSBERG, 2009, p. 71) e afetivas, que engendram, ao mesmo tempo, tanto processos constitutivos de novas corporeidades - evidenciando assim o modo como ele, o corpo, cria e experimenta suas micro-revoluções cotidianas - quanto processos constitutivos de obras, que num sentido plural "interferem de maneira crítica e contundente sobre o funcionamento dos códigos do vivido" (SILVA, 2011, p. 98).

Nota-se aí, o quanto o segundo ponto de partida primordial da singularidade poética de Rubiane Maia parece se conformar como uma espécie de dobra do primeiro. Nesse, ao operar a busca pelas possibilidades de expansão das próprias potências do corpo - a partir do intercâmbio entre os fluxos e as intensidades mobilizadas à medida que processo e obra são sobrepostos em suas ações - o corpo é acionado como uma entidade processual, na qual o processo se torna crucial não só à constante invenção e reinvenção de suas corporeidades, mas, também, à constituição de suas obras.

Dinâmica processual cujas obras e corporeidades gestadas no cerne de suas ações performativas provocam o estremecimento e o esgarçamento dos contornos do corpo e do mundo. Exortam, com todo vigor, a potência do corpo biopolítico - aquele que toma posse do poder da vida, mobiliza afetos, promove mutações no mundo, reorienta a consistência sensível da subjetividade, prolifera devires. Em outras palavras, obras que forjam no corpo passagens que conduzem a constituição de corporeidades sensíveis, mais vivas e vibráteis (ROLNIK, 2011; 2018), bem como corporeidades que inoculam, portanto, a alteridade, a heterogeneidade e o outramento.

Por fim, se o corpo - tomado em sua realidade sensível - se constitui como meio pelo qual percola a ideia de volução do tempo da criação dos processos artísticos de Rubiane Maia, faz-se mister observar, em terceiro lugar, que é em direção ao plano dos seus próprios processos de subjetivação $0^{11}$ que a atividade de criação é mobilizada em sua espiral poética. A respeito desta questão, diz ela:

\footnotetext{
11 De acordo com Leila Domingues (1999, p. 2), "há uma distinção entre modos de subjetivação - processos de subjetivação ou modos de existência - e formas-subjetividade, como aspectos presentes na constituição da subjetividade. A subjetividade nos fala de territórios existenciais que podem tornar-se herméticos às transformações possíveis, como mapas, ou podem tornar-se abertos a outras formas de ser, como nas cartografias. Os modos de subjetivação referem-se à própria força das transformações, ao devir, ao intempestivo, aos processos de dissolução das formas dadas e cristalizadas, uma espécie de movimento instituinte que ao se instituir, ao configurar um território, assumiria uma dada forma-subjetividade. Os modos de subjetivação também, são históricos, contudo, tem para com a história uma relação de processualidade e por isso não cessam de engendrar outras formas".
} 
eu acho que quando entrei no mestrado, e comecei a estudar as correntes filosóficas, toda essa bibliografia em torno dessa ideia de clínica da psicologia institucional, desse questionamento dos efeitos da institucionalização na produção de subjetividade, eu encontrei um chão pra mim muito forte que respondia questões que eu pensava de uma maneira muito intuitiva" (SILVA, 2020 apud AL-

VES, 2020, p. 126).

\section{E continua:}

eu acho que minha performance, o meu trabalho, continuam conectados com a clínica. Algo que nasce desse processo de encontro com essa perspectiva da clínica, que nasce desse processo de encontro com o mestrado, e aí isso é uma coisa que eu não abandonei"

(Ibidem, p. 126).

A perspectiva clínica a que Rubiane se refere é justamente aquela que vem pautando a possibilidade de reconfiguração do campo psi, qual seja, a perspectiva clínico-institucional, que "possibilita a emergência de práticas que tomam o caráter histórico, contingente, inacabado e múltiplo do sujeito como potência afirmadora e engendradora de novos modos de existência" (ESCÓSSIA \& MANGUEIRA, 2005, p. 94). Perspectiva que vem instituindo caminhos alternativos e de resistência aos modos hegemônicos de institucionalização dos processos de subjetivação em voga.

É junto a essa perspectiva clínica que Rubiane Maia mobilizará - de modo bastante consciente - sua atenção ao campo pungente de problematização sobre os processos contínuos de produção de modos de existência, que mais tem nos conduzido ao padecimento do que à potência de agir. É junto a ela, ainda, que sintonizará sua escuta ao aqui e agora do campo invisível de forças e afetos que, em vias de constituição, não cessam de convocar maneiras singulares de viver - as quais afirmam a vida em sua potência criadora, enquanto força de invenção - mais aquém e mais além dos padrões, normas e regras estabelecidas. É junto a ela, também, que afirmará, com maior vigor, que "recriar a si mesmo e a própria vida é um processo infinito de alçar sempre novas composições de si mesmo e do mundo" (SILVA, 2011, p. 68). É junto a ela, inclusive, que passará a apostar em uma

positividade criadora e inventiva pela construção de práticas artísticas que na sua atuação poética tanto no campo da produção/ criação, como no campo da recepção/participação, compõem um feixe de relações capazes de gerar outros modos de partilha e subjetivação que escapam aos modelos

(Ibidem, p. 69).

Perceba o quanto a nossa potência de agir está intrinsecamente atrelada à liberação do desejo (DELEUZE \& GUATTARI, 2004) de uma certa organização social que nos faz viver uma vida de baixas intensidades. E Rubiane, rapidamente, se atém a isso. Ou seja, a fazer fugir seu desejo em busca de novos territórios existenciais ético-estéticos (GUATTARI, 1992), operando-os como espécies de usinas nas quais o desejo, além de desejar a si mesmo, aumenta a sua própria potência de agir em direção ao agenciamento de outros afetos, outras cotidianidades, outras corporeidades, outros pensamentos e, portanto, outras subjetividades. Como ela mesma faz questão de frisar, "nesses movimentos de maior vigor rumo às singularidades e à criação de dispositivos, a proposição de novos jogos de resistência e liberdade assumem uma posição de extrema importância" (SILVA, 2011, p. 69), afinal de contas, "nossa força de existir pulsa muito mais pela construção dessas vias de escape do que de espaços e tempo de confinamentos" (Ibidem, p. 69) do desejo.

Apropriar-se do desejo implica, em Rubiane 
Maia, a afirmação deste movimento como algo capaz de deflagrar a potência de possíveis, nos quais a vida não cessa de jorrar enquanto força de invenção. Atitude que não só coloca uma espécie de lente de aumento sobre a sua produção ativa de subjetividade, a sua autocriação processual, como, também, dá a vê-la, ao mesmo tempo, como um empreendimento ético, estético e político da criação de si - uma vez que, como ela mesma nos lembra, "a crise da vida é a crise da ética, da política e da estética" (Ibidem, p. 70).

Empreendimento no qual o amálgama entre seus processos de vida e processos artísticos passa a ser mobilizado em favor da instauração de outros processos de subjetivação de si. Processos que suscitam a cartografia de novas paisagens, novos ares, novas nuances de mundo, novos fluxos de desejos e afetos, possibilitando, assim, que sua vida escolha ou mesmo forje as forças com as quais se irá compor em direção à criação de novos modos de existência (DOMINGUES, 2010). Amálgama que parece atuar no entrecruzamento das proposições de Lygia Clark com os empreendimentos filosóficos de Friedrich Nietzsche e Michel Foucault. Afinal de contas, trata-se de um amálgama no qual o próprio ato de ato de criar se torna obra (ROLNIK, 2000); processo sem fim que toma a vida como experimento, que assume a criação de si como uma obra a ser investida (NIETZSCHE, 1992; 2001) - em suma, que faz da sua própria vida uma obra de arte (FOUCAULT, 1984; 1985).

Amálgama visivelmente clínico e, portanto, explicitamente ethopoético ${ }^{12}$. A esse respeito,

12 Para Leila Domingues (2017, p. 183), "o termo ethopoética se faz da conexão entre os termos êthos, palavra de origem grega cujo significado seria ética, modos de vida, processo de constituição de si ou governo de si como sujeito moral e político; e poética, que significa criação. Ethopoética, portanto, diz da criação, a constituição, a invenção de si como sujeito, em suas dimensões estéticas, éticas e políticas".
Rubiane nos diz: "Sim, há desdobramentos clínicos nas minhas ações, que agem sobre mim, e sobre o que está ao meu redor porque tudo é interdependente - o nosso modo de agir é uma questão ética" (SILVA, 2018 apud ALVES, 2020, p. 129). Neste breve depoimento, a artista parece nos lembrar que a invenção de novas possibilidades de vida - urdidas no seio de suas práticas artísticas - não é apenas estética.

Isso porque, ao operar a clínica como clínica de si - terreno prolífico à construção de um êthos do cuidado de si - suas ações também são atravessadas por uma prática ética de produção de subjetividade cujo gesto é eminentemente político - posto que nele, o próprio mundo passa a fazer-se e refazer-se junto à subjetividade que aí se anuncia. Assim, é na proximidade criadora entre as dimensões ética, estética e política que Rubiane Maia faz vibrar forças que operam em sua vida movimentos de diferenciação, mobilizando, consequentemente, a ética como um exercício de liberdade (FOUCAULT, 2004) que tanto afirma a vida como potência criadora quanto convoca seu saber-fazer artístico a investir e agir junto a ela.

Nota-se aí, o quanto o terceiro ponto de partida primordial da singularidade poética de Rubiane Maia parece se conformar como uma espécie de dobra dos dois anteriores e, ao mesmo tempo, plano sobre o qual todos eles se entrecruzam, se entrelaçam e voluem. Aqui, ao perseguir e forjar, para si mesma, modos outros de produção de subjetividade - via uma perspectiva expansiva de suas práticas que instauram uma certa zona de indiscernibilidade entre vida e obra, ponto de indistinção entre processos de vida e processos artísticos - é a própria existência de Rubiane que passa a ser alvo de seu saber-fazer artístico. Em outras palavras, é sobre a sua própria vida e o que está a sua volta que seu tempo da criação se debruça e volui. 
Isso significa que, em Rubiane Maia, cada projeto, cada performance, cada experiência - no sentido mais largo do termo - são mobilizados como espécies de práticas de si. Práticas que, voltadas ao trabalho sobre si mesma, tornam-se capazes de engendrar novos territórios existenciais nos quais sua vida evoque, descubra e extraia o que de singular nela se encontra em vias de devir. Práticas que assumem os processos artísticos, portanto, como laboratório de constantes procedimentos de experimentação de formas-subjetividades que convoquem à criação e à recriação de si mesma e de sua visão de mundo. Espaço-tempo em que sua vida é posta em jogo, e não somente com objeto e meio de sua arte, mas, principalmente, como instância através da qual se é possível tanto vislumbrar novos modos de vida quanto modificar seu próprio ser, sua própria vida.

\section{Notas (in)conclusivas: por um horizonte mais expansivo de relações entre a arte e a vida}

Bem, se é a vida, ou melhor, a própria vida de Rubiane Maia, que é o foco de suas dobraduras poéticas - que se fazem, desfazem e refazem em movimentos incessantes, forjados nesse seu tempo de criação espiralado - atribuindo direção e sentidos aos deslocamentos de sua construção poética, torna-se impossível falar deles sem tocar nos seus processos de vida, e vice-versa. Em Rubiane, todo percurso artístico é percurso de vida. E, enquanto tal, parece fazer ainda mais sentido a aproximação estabelecida entre a noção serresiana de tempo como multiplicidade pura e o tempo da criação mobilizado pela artista em seus múltiplos processos artísticos/processos de vida.

Se considerarmos que o fazer artístico de Rubiane se realiza em um aqui-agora que agencia passado, presente e futuro simultaneamente, podemos conjecturar que esse seu fazer tem a ver com o vetor de ativação da criação da vida que afirma o tempo à luz da multiplicidade. Isso porque a invenção de novos modos de existência envolve e evoca, por si só, a sincronia de vários tempos em direções diversas, num fluxo que pressupõe aproximações, afastamentos, tangências, atritos e contaminações com as matérias de expressão do mundo. Algo que parece nos conduzir ao seguinte entendimento: se não é possível atribuir uma direção unívoca ao tempo - como nos lembram Michel Serres (1982; 1999) e Bruno Latour (1994) - isso se deve, em grande medida, ao caráter criador da vida que arrasta uma gama de processualidades espácios-temporais que escapam a qualquer tipo de sobrecodificação teleológica.

Nesse sentido, em Rubiane Maia, não são somente os processos artísticos que se revelam como politemporais, mas, também, os próprios processos de vida. Em cada ação, a artista opera a dobra de sua vida, aproximando tempos, espaços, circunstâncias e forças distanciadas; e distanciando tempos, espaços, circunstâncias e forças próximas. Dobras que mobilizam a constituição de formas-subjetividades provisórias que engendram ilimitadas combinações de existências possíveis. Dobras que entrelaçam, misturam e embaralham as matérias de expressão que, em vias de constituição ante a existência que devém em cada ação, atribuem tonos e singularidade à sua poética.

Apostar nesses atravessamentos politemporais - resultados das dobras que a artista opera em sua própria vida - faz com que sua poética seja permanentemente ativada e reativada, sob o signo da diferença. Cada dobra parece tensionar uma volta a mais nessa espécie de espiral poética que diz respeito, ao mesmo tempo, aos seus percursos artísticos e percursos de vida - uma vez que é por meio dela que 
o tempo da criação de si e do fazer artístico de Rubiane Maia voluem simultaneamente, tornando-se, inclusive, indiscerníveis. Nessa espiral poética, cotidiano, corpo e processos de subjetivação demarcam presença. Além de comparecerem em articulações, composições e intensidades distintas - nas quais é a vazão do desejo de outrar-se de Rubiane que está em questão - essas presenças tornam-se peças e engrenagens uma das outras, nutrindo o modo singular como Rubiane Maia toca e agencia, em seu fazer artístico, atualidade e da pertinência da proposta de aproximação entre arte, vida e obra na contemporaneidade. A esse respeito, ela mesma nos diz: "Mais do que misturar arte e vida, o que queremos é apresentar uma perspectiva mais expansiva de relações entre a arte e a vida" (SILVA, 2011, p. 113).

Assim, ao dispor arte, vida e obra no mesmo plano de voluções de sua espiral poética, Rubiane acaba suscitando em seus processos artísticos, invariavelmente, a reflexão sobre o poder inquietante e provocador que o ser obra da obra de arte (AGAMBEN, 2013) pode promover ao saber-fazer artístico na condição histórica do presente. E podemos entender isso de duas maneiras: uma primeira ligada às potencialidades do saber-fazer artístico em "distender a criação de novos processos de subjetivação" (SILVA, 2011, p. 113), nos quais a vida possa se constituir como pura vontade de potência (NIETZSCHE, 2013); e, uma segunda, ligada a ideia de que a criação de si como obra a ser investida - tomada, simultaneamente, como problema ético, estético e político do saber-fazer artístico - constituiria, em si, uma via prolífica tanto de conjugação de um pensamento crítico acerca de nós mesmos e do modo como estamos conduzindo as nossas vidas, quanto de contestação dos próprios regimes de (in)visibilidade das relações sistêmicas da arte.
Em ambos os casos, ao escapar da lógica do encadeamento cronológico - embaralhando e, no limite, abandonando o tempo linear, proliferando para além dele - o que estaria em jogo seria a desobstrução da dimensão estética da subjetividade, ao afirmar a vida como perpétua atividade criadora. Vetores que conduzem a instauração da práxis vital como nascedouro de novas e potentes dimensões da criação, distintas das exortadas pelos sistemas de valores essencialmente artísticos. Vetores cujas considerações que evocam impõem a necessidade em termos de lidar permanentemente com os desafios teórico-crítico colocados pelo caráter, por natureza, processual, dinâmico e politemporal, da criação que transborda o ato criador e a obra em direção à indissociação entre vida e obra - não por acaso, uma entre tantas e difusas características das poéticas artísticas contemporâneas (SALLES, 2006).

\section{Referências}

AGAMBEN, Giorgio. Arqueologia da obra de arte. Tradução Vinícius Nicastro Honesko. In: Princípios, Natal, v. 20, n. 34, p. 349-361, jul.dez. 2013. Disponível em: <https://periodicos. ufrn.br/principios/article/view/7549>. Acesso em: 29 jan. 2019.

ALVES, Lindomberto Ferreira. Arte e vida em obra: a poética biografemática de Rubiane Maia. 2020. 330 f. Dissertação (Mestrado em Artes) - Programa de Pós-Graduação em Artes, Centro de Artes, Universidade Federal do Espírito Santo, Vitória, 2020.

DELEUZE, Gilles. A dobra: Leibiniz e o barroco. Tradução Luiz Orlandi. Campinas: Papirus, 1991.

DELEUZE, Gilles; GUATTARI, Félix. O Anti-Édipo: Capitalismo e esquizofrenia. Tradução Joa- 
na Varela e Manuel Maria Carrilho. Lisboa: Assírio \& Alvim, 2004.

DOMINGUES, Leila. Subjetividades contemporâneas. In: BARROS, Maria Elizabeth Barros (org.). Psicologia: questões contemporâneas. Vitória: EDUFES, 1999. p.1-22.

À flor da pele: subjetividade, clínica e cinema no contemporâneo. Porto Alegre: Sulina, 2010.

Ensaios de subjetivação: ethopoética, cartografemas e ethografias. In: LEÃO, Adriana et al (org.). Produção de subjetividade e institucionalismo: experimentações políticas e estéticas. Curitiba: Appris, 2017. p. 181-197.

ESCÓSSIA, Liliana da; MANGUEIRA, Maurício. Para uma psicologia clínico-institucional a partir da desnaturalização do sujeito. In: Revista do Departamento de Psicologia - UFF, Niterói, v. 17, n. 1, p. 93-101, jan.-jun 2005. Disponível em: <https://www.scielo.br/pdf/rdpsi/v17n1/ v17n1a07.pdf>. Acesso em: 13 ago. 2019.

FOUCAULT, Michel. História da sexualidade, vol. II: O uso dos prazeres. Tradução Maria Thereza da Costa Albuquerque. Rio de Janeiro: Graal, 1984.

História da sexualidade, vol. III: O cuidado de si. Tradução Maria Thereza da Costa Albuquerque. Rio de Janeiro: Graal, 1985.

- A ética do cuidado de si como prática da liberdade. In: FOUCAULT, Michel. Ética, sexualidade, política. Coleção Ditos \& Escritos, vol. V. Tradução Elisa Monteiro e Inês Autran Dourado Barbosa. Rio de Janeiro: Forense Universitária, 2004, p. 264-287.

O nascimento da biopolítica. Tradução Eduardo Brandão. São Paulo: Martins Fontes, 2008.

GLUSBERG, Jorge. A arte da performance. Tradução Renato Cohen. São Paulo: Perspectiva, 2009.

GUATTARI. Félix. Caosmose: um novo paradigma estético. Tradução Ana Lúcia de Oliveira \& Lú- cia Cláudia Leão. Rio de Janeiro: Editora 34, 1992.

LATOUR, Bruno. Jamais fomos modernos: ensaios de antropologia simétrica. Tradução Carlos Irineu da Costa. Rio de janeiro: Editora 34, 1994.

MBEMBE, Achille. Necropolítica: biopoder, soberania, estado de exceção, política da morte. Tradução de Renata Santini. São Paulo: N-1 edições, 2018.

MEDEIROS, Maria Beatriz de. Sugestões de conceitos para reflexão sobre a arte contemporânea a partir da teoria e prática do grupo de pesquisa corpos informáticos. In: ARJ, Natal/ Porto Alegre, v. 4, n. 1, p. 33-47, jan.-jun. 2017. Disponível em: <https://periodicos.ufrn.br/artresearchjournal/article/view/11808/8698>. Acesso em: 10 de mar. de 2020.

NIETZSCHE, Friedrich. O nascimento da tragédia, ou Helenismo e pessimismo. Tradução Jacó Guinsburg. São Paulo: Companhia das Letras, 1992.

A gaia ciência. Tradução Paulo César de Souza. São Paulo: Companhia das Letras, 2001.

Assim Falava Zaratustra. Tradução Antonio Carlos Braga. São Paulo: Escala, 2013.

ROLNIK, Suely. O corpo vibrátil de Lygia Clark. In: Folha de São Paulo, São Paulo, 30 de abr. de 2000. Disponível em: <https://www1.folha.uol. com.br/fsp/mais/fs3004200006.htm>. Acesso em: 10 mar. 2020.

. Cartografia sentimental: transformações contemporâneas do desejo. São Paulo: Estação Liberdade, 2011.

___. Esferas da insurreição: notas para uma vida não cafetinada. São Paulo: N-1 edições, 2018.

SALLES, Cecília Almeida. Redes da criação: construção da obra de arte. Vinhedo: Horizonte, 2006.

SANTOS, Milton. Por uma Geografia cidadã: por uma epistemologia da existência. In: Boletim Gaúcho de Geografia, Porto Alegre, v. 21, n. 1, p. 7-14, ago. 1996. p. 10. Disponível em: <https://seer.ufrgs.br/bgg/article/view/38613>. Acesso em: 10 mar. 2020. 
SERRES, Michel. Le système de Leibniz et ses

modèles mathématiques. Paris: P.U.F., 1968.

Genèse. Paris: Grassei, 1982.

Luzes: cinco entrevistas com Bruno Latour. Tradução de Luiz Paulo Rouanet. São Paulo: Unimarco, 1999.

SILVA, Rubiane Vanessa Maia da. Desvios, sobre arte e vida na contemporaneidade. 2011. 142 f. Dissertação (Mestrado em Psicologia Institucional) - Programa de Pós-Graduação em Psicologia Institucional, Departamento de Psicologia, Universidade Federal do Espírito Santo, Vitória, 2011.

VINÍCIUS, Marcus. Cotidiano: reflexões atuais e (in)oportunas. In: Revista Tatuí, n. 8, p. 24-26, 2010. Disponível em: <http://www.revistatatui. com.br/colaboradores/marcus-vinicius/>. Acesso em: 10 mar. 2020.

\section{Lindomberto Ferreira Alves}

Artista-educador, pesquisador, crítico e curador independente. Mestre em Teoria e História da Arte pelo PPGA-UFES (2018/20). Licenciando em Artes Visuais pela UNAR/SP (2020) e Bacharel em Arquitetura e Urbanismo pela UFBA (2013). É membro do grupo de pesquisa "Curadoria e Arte Contemporânea” e integra a equipe da "Plataforma de Curadoria" (DAV-UFES), plataforma virtual focada nos processos de criação em curadoria. Possui textos publicados em livros, catálogos e revistas especializados nos campos da história, teoria e crítica de arte. Suas investigações privilegiam a análise dos processos de criação na arte contemporânea, de modo especial, no estudo de produções cujos processos criativos colocam arte, vida e obra no mesmo plano de contágio. 